\title{
ANATOMIA DA MADEIRA DE BERBERIS LAURINA BILLB. ${ }^{1}$
}

\author{
JOSÉ NEWTON CARDOSO MARCHIORI² LUCIANO DENARDI ${ }^{3}$
}

\section{RESUMO}

A estrutura anatômica da madeira de Berberis laurina Billb. é descrita e ilustrada com fotomicrografias. Palavras-chave: Anatomia da madeira, Berberidaceae, Berberis laurina.

\section{ABSTRACT}

The wood anatomy of Berberis laurina Billb. is described and illustrated with photomicrographs.

Key words: Wood anatomy, Berberidaceae, Berberis laurina.

\section{INTRODUÇÃO}

As Berberidáceas compreendem 14 gêneros e cerca de 200 espécies, nas regiões temperadas do Hemisfério Norte e América do Sul (Pontiroli, 1967), distinguindo-se, juntamente com as Menispermáceas e Ranunculáceas, pela presença de berberina nos tecidos vegetais (Marchiori, 1997).

O gênero Berberis L. é o mais numeroso da família e o único representado no hemisfério austral. Com cerca de 170 espécies de arbustos e árvores pequenas na América do Sul, o gênero distribui-se ao longo dos Andes, alcançando o extremo sul da Argentina (Troncoso, 1987). Para o Estado de Santa Catarina, Mattos (1967) relaciona apenas Berberis laurina e Berberis kleinii. Sob o ponto de vista florístico, o gênero integra o "contingente andino" (Rambo, 1951), ao lado de Podocarpus, Araucaria, Escallonia, Roupala, Weinmannia, Drimys e Quillaja, entre outros. Em estudo mais recente, Waechter (2002) inclui Berberis L. entre os gêneros holárticos.

Arbusto de espinhos trífidos e lenho amarelo, Berberis laurina Billb. apresenta folhas coriáceas de 3-9 $\mathrm{cm}$ de comprimento, íntegras ou com dentes espinescentes, dispostas alternadamente ou em curtos raminhos que simulam folhas verticiladas (Lombardo, 1982). As flores, amarelo-claras, dispõem-se em pequenos racemos pendentes e os frutos, bacáceos e de cor negra, medem de 5-7 $\mathrm{mm}$ de comprimento por 3-5 mm de diâmetro (Mattos, 1967). Nativa de Minas Gerais até o Uruguai, a espécie é popularmente conhecida como espinho-de-SãoJoão, espinho-de-São-Simão, São-João (Schultz, 1975), berbéris-da-terra, quina-cruzeiro, uva-deespinho (Pio Corrêa, 1984), espina-amarilla (Lombardo, 1982) e palo-amarillo (Herter, 1930).

Sobre a anatomia das Berberidáceas, Metcalfe \& Chalk (1972a) relacionam a presença de vasos muito pequenos, em padrão radial ou ulmiforme, de elementos vasculares extremamente curtos, com placas de perfuração simples, pontoações alternas e espessamentos espiralados na parede, de raios homogêneos, tipicamente altos e largos, e de fibras extremamente curtas, septadas em alguns gêneros e com pequenas pontoações simples na parede. Cabe também salientar a ausência de parênquima axial e a estratificação de elementos vasculares (Record \& Hess, 1949). O conjunto desses caracteres anatômicos permite considerar as Berberidáceas

\footnotetext{
Artigo recebido em 19/04/2005 e aceito para publicação em 30/05/2005.

2 Engenheiro Florestal, Dr., bolsista de Produtividade em Pesquisa do CNPq, Professor Titular do Departamento de Ciências Florestais, Universidade Federal de Santa Maria, CEP 97105-900, Santa Maria (RS). balduinia@mail.ufsm.br

3 Engenheiro Florestal, bolsista do CNPq, doutorando do Programa de Pós-Graduação em Engenharia Florestal, Universidade Federal de Santa Maria, CEP 97105-900, Santa Maria (RS). lucianodenardi@yahoo.com.br
} 

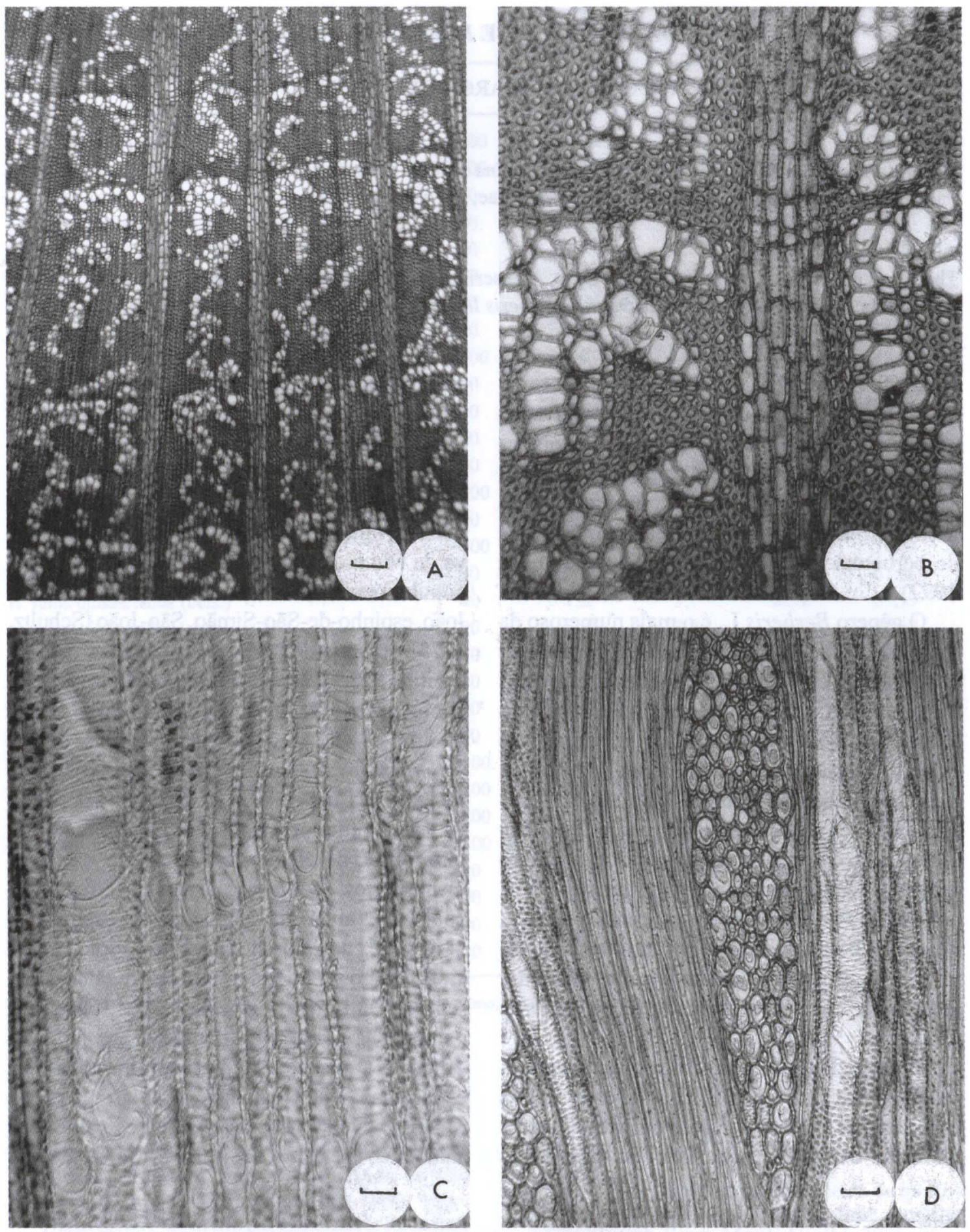

FIGURA 1 - Seção transversal, destacando a porosidade semi-difusa, em padrão dendrítico (A). Poros pequenos de seção poligonal e fibras de paredes delgadas, em seção transversal (B). Elementos vasculares estratificados, com espessamentos espiralados e placas de perfuração simples, em seção longitudinal radial (C). Raios multisseriados, com células envolventes e placas de perfuração oblíquas, em seção longitudinal tangencial (D). Escalas $=100 \mu \mathrm{m}(\mathrm{A}) ;=25 \mu \mathrm{m}(\mathrm{B}, \mathrm{D}) ;=50 \mu \mathrm{m}(\mathrm{C})$. 

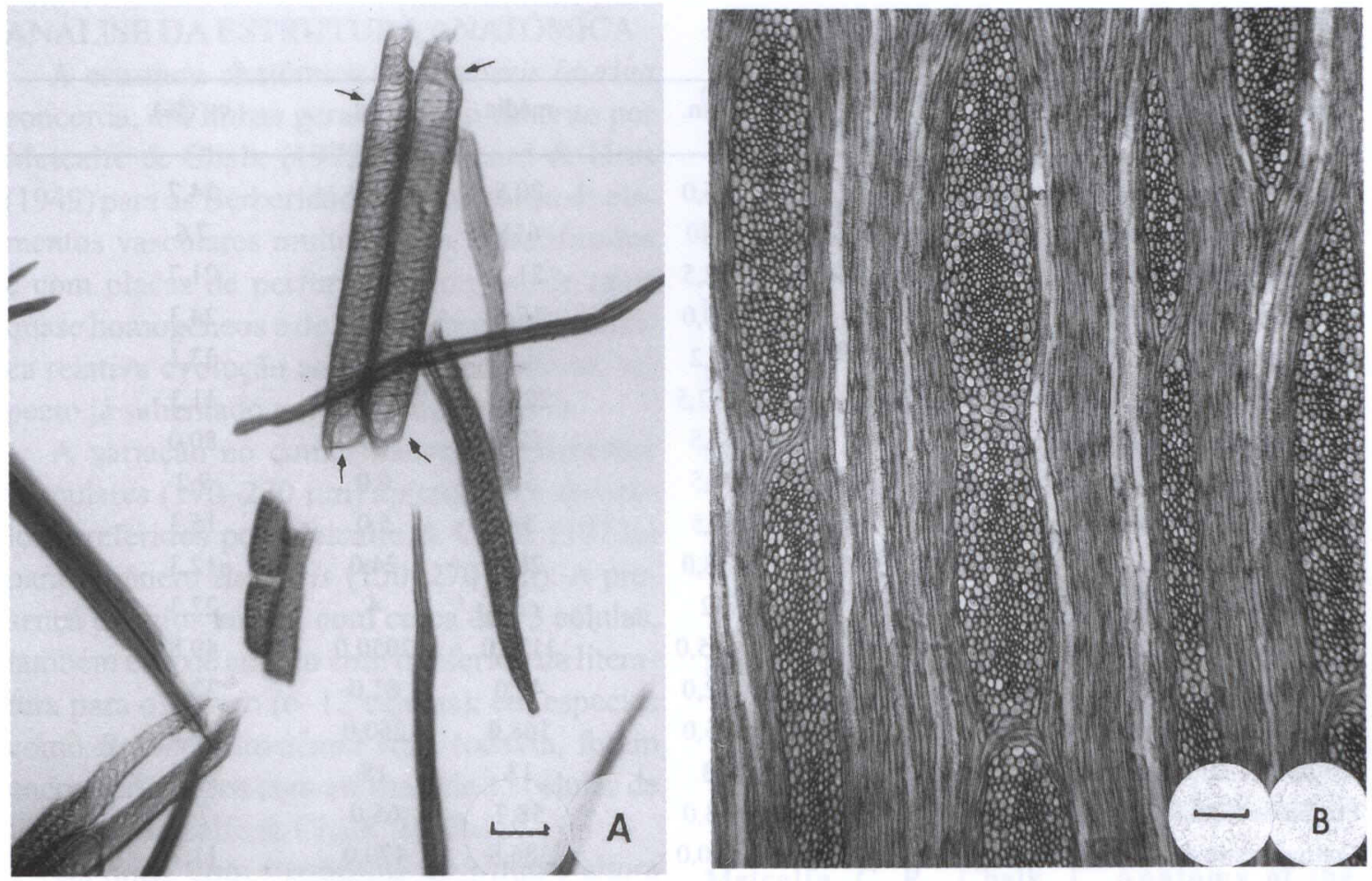

FIGURA 2 - Fibras e elementos vasculares com apêndices curtos (setas), em lâmina de macerado (A). Raios agregados, com células procumbentes de diâmetros variados, em seção longitudinal tangencial (B). Escalas $=50 \mu \mathrm{m}(\mathrm{A}) ;=100 \mu \mathrm{m}(\mathrm{B})$.

como família botânica moderadamente evoluída (Marchiori, 1997).

\section{MATERIAL E MÉTODOS}

$\mathrm{O}$ material em estudo foi coletado em Pedras Altas (Pinheiro Machado - RS) e anexado à Xiloteca e Herbário do Departamento de Ciências Florestais da Universidade Federal de Santa Maria (HDCF), sob o número 1777.

Da amostra de madeira, foram confeccionados três corpos-de-prova com $2 \mathrm{~cm}$ de lado, extraídos da porção mais externa do lenho e orientados para a obtenção de cortes histológicos nos planos transversal, longitudinal radial e longitudinal tangencial. Um quarto bloco foi também retirado, com vistas à maceração.

No preparo de lâminas histológicas, seguiuse a técnica padrão no Laboratório de Anatomia da Madeira da Universidade Federal do Paraná: os corpos-de-prova foram amolecidos por fervura em água e seccionados em micrótomo de deslize, regulado para a espessura nominal de $18 \mu \mathrm{m}$. Os cortes foram tingidos com acridina-vermelha, crisoidina e azul-de-astra (Dujardin, 1964), desidratados em séria alcoólica, diafanizados em xilol e montados em lâminas permanentes, com "Entellan".

Para a dissociação do tecido lenhoso, usouse o método de Jeffrey (Burger \& Richter, 1991), seguido de coloração com safranina $1 \%$ e montagem de lâminas permanentes, com "Entellan".

A descrição microscópica baseou-se nas normas da COPANT (1973), com as alterações propostas por Burger (1979) e Marchiori (1980). As fotomicrografias foram tomadas em aparelho Carl Zeiss, no Laboratório de Anatomia da Madeira da Universidade Federal do Paraná.

\section{DESCRIÇÃO MICROSCÓPICA}

Vasos: Extremamente numerosos (540-615668 poros $/ \mathrm{mm}^{2}$ ) e em distribuição semi-difusa (Figura 1A), ocupando cerca de $20 \%$ da seção 
TABELA 1: Dados quantitativos da madeira.

\begin{tabular}{lcccc}
\hline Característica anatômica & min. & média & máx. & cv (\%) \\
\hline Fração de poros (\%) & 16,0 & 20,5 & 24,0 & 14,7 \\
Freqüência de poros (poros $\left./ \mathrm{mm}^{2}\right)$ & 540 & 615 & 668 & 7,6 \\
$\varnothing$ poros $(\mu \mathrm{m})$ & 12,5 & 21,3 & 32,5 & 21,7 \\
$\varnothing$ lume de poros $(\mu \mathrm{m})$ & 10,0 & 17,4 & 27,5 & 24,3 \\
Espessura parede dos poros $(\mu \mathrm{m})$ & 1,2 & 1,9 & 2,5 & 33,1 \\
Comprimento de elementos vasculares $(\mu \mathrm{m})$ & 172,5 & 229,1 & 270,0 & 11,3 \\
Comprimento de apêndices $(\mu \mathrm{m})$ & 7,5 & 22,4 & 90 & 80,0 \\
$\varnothing$ pontoações intervasculares $(\mu \mathrm{m})$ & 4,5 & 5,4 & 6,0 & 9,2 \\
$\varnothing$ pontoações rádio-vasculares $(\mu \mathrm{m})$ & 2,5 & 3,6 & 5,0 & 15,3 \\
Fração de raios $(\%)$ & 18,0 & 20,8 & 24,0 & 12,3 \\
Freqüência de raios (raios/mm) & 2 & 3 & 4 & 22,3 \\
Altura de raios multisseriados $(\mu \mathrm{m})$ & 125,0 & 1117,0 & 2050,0 & 40,8 \\
Altura de raios multisseriados $($ células) & 22,0 & 49,0 & 81,0 & 32,4 \\
Largura de raios multisseriados $(\mu \mathrm{m})$ & 45,0 & 168,0 & 250,0 & 29,3 \\
Largura de raios multisseriados $($ células) & 3 & 13 & 18 & 24,3 \\
Fração de fibras $(\%)$ & 53,0 & 58,7 & 65,0 & 7,0 \\
Comprimento de fibras $(\mu \mathrm{m})$ & 290,0 & 386,8 & 470,0 & 11,7 \\
$\varnothing$ total de fibras $(\mu \mathrm{m})$ & 12,5 & 14,6 & 17,5 & 10,1 \\
$\varnothing$ lume de fibras $(\mu \mathrm{m})$ & 6,2 & 8,4 & 11,3 & 15,5 \\
Espessura parede de fibras $(\mu \mathrm{m})$ & 2,5 & 3,1 & 3,8 & 14,5 \\
\hline
\end{tabular}

mín. = valor mínimo; máx. = valor máximo; $\mathrm{cv} \%=$ coeficiente de variação; $\mu \mathrm{m}=$ micrômetros; $\emptyset=$ diâmetro.

transversal da madeira. Vasos em padrão dendrítico; extremamente pequenos (10-17-27 $\mu \mathrm{m}$ ), de seção poligonal e com paredes de 1,2 $1,9-2,5 \mu \mathrm{m}$ de espessura (Figura 1A, B). Elementos vasculares muito curtos (172-229-270 $\mu \mathrm{m})$ e estratificados, providos de apêndices curtos (7-22-90 $\mu \mathrm{m})$ e espessamentos espiralados na parede (Figura 1C, 2B). Placas de perfuração simples, oblíquas (Figura 1C, D). Pontoações intervasculares alternas, pequenas $(4,5-5,4-6,0 \mu \mathrm{m})$ e poligonais, com abertura lenticular inclusa; pontoações rádio-vasculares pequenas e arredondadas $(2,5-3,6-5,0 \mu \mathrm{m})$. Gomas, resinas e tilos, ausentes nos vasos.

Parênquima axial: Ausente.

Raios: Pouco numerosos (2-4/mm), ocupando $21 \%$ do volume da madeira. Tecido radial homogêneo a fracamente heterogêneo, por vezes com células quadradas nas extremidades, composto por células procumbentes de diâme- tros variados em seção longitudinal tangencial (Figura 2A). Raios exclusivamente multisseriados e por vezes agregados (Figura 2A), com células envolventes (Figura 1D). Raios com mais de 4 células de largura, com escassos tetrasseriados e trisseriados; variam de muito baixos a muito altos (125-1117-2050 $\mu \mathrm{m})$, com 22-49-81 células de altura, e de finos a muito largos (45-168-250 $\mu \mathrm{m})$, com 3-13-18 células de largura (Figura 1D, 2A).

Fibras: Tecido fibroso proeminente $(59 \%)$, composto de fibras libriformes não septadas (Figura 1D) extremamente curtas (290-387-470 $\mu \mathrm{m}$ ), estreitas $(6,2-8,4-11,3 \mu \mathrm{m})$ e de paredes delgadas, com 2,5-3,1-3,8 $\mu \mathrm{m}$ de espessura (Figura 1B).

Outras características: Anéis de crescimento marcados por fibras radialmente estreitas no lenho tardio e poros de maior diâmetro no inicio do anel seguinte (Figura 1A, B). 
ANÁLISE DA ESTRUTURA ANATÔMICA

A estrutura anatômica de Berberis laurina concorda, em linhas gerais, com o descrito por Metcalfe \& Chalk (1972a) e Record \& Hess (1949) para as Berberidáceas. A presença de elementos vasculares muito curtos, estratificados e com placas de perfuração simples, de raios quase homogêneos e de fibras libriformes, indica relativa evolução ao xilema secundário, aspecto já salientado por Marchiori (1997).

A variação no comprimento de elementos vasculares (170-270 $\mu \mathrm{m})$ aproxima-se dos valores referidos por Metcalfe \& Chalk (1972a) para o gênero Berberis $(150-270 \mu \mathrm{m})$. A presença de raios largos, com cerca de 13 células, também está de acordo com o referido na literatura para o gênero (6-12 células); em espécies como Berberis kavacana Hay, todavia, foram encontrados raios com até mais de 25 células de largura (Metcalfe \& Chalk, 1972a).

Os raios, com freqüência de $3 / \mathrm{mm}$ e altura superior a $1 \mathrm{~mm}$, subdividem-se, por vezes, em unidades menores, aspecto também referido para Berberis kavacana. A presença de células envolventes, observada no material em estudo, foi também assinalada para Berberis darwinii Hook., por Metcalfe \& Chalk (1972a).

$\mathrm{Na}$ espécie em estudo, os valores de comprimento de fibras $(290-470 \mu \mathrm{m})$ concordam com o referido na literatura $(300-750 \mu \mathrm{m})$ sobre o gênero. Cabe salientar, ainda, a ausência de parênquima axial no material examinado; essa estrutura, comum à grande maioria das angiospermas dicotiledôneas, é também ausente no lenho de algumas Flacurtiáceas (Burger \& Richter, 1991) e Apocináceas de fibras septadas (Metcalfe \& Chalk, 1972b).

\section{BIBLIOGRAFIA}

Burger, L. M., Richter, H. G. Anatomia da Madeira. São Paulo: Ed. Nobel, 1991. 154 p.

Burger, L. M. Estudo anatômico do xilema secundário de sete espécies nativas do gênero Dalbergia, Leguminosae-Faboideae. Curitiba: UFPR, 1979. 184f. Dissertação (Mestrado em
Engenharia Florestal) - Universidade Federal do Paraná.

Copant - Comissão Panamericana de Normas Técnicas. Descrição macroscópica, microscópica e geral da madeira - esquema I de recomendação. Colômbia, 1973. 19p. (COPANT 30).

Dujardin, E. P. Eine neue Holz-Zellulosenfaerbung. Mikrokosmos, n. 53, p. 94, 1964.

Herter, G. Estudios botánicos en la región uruguaya. Montevideo: 1930.191p.

Lombardo, A. Flora Montevidensis. Montevideo: Intendencia Municipal, 1982. v. 1. 316p.

Marchiori, J. N. C. Estudo anatômico do xilema secundário de algumas espécies dos gêneros Acacia e Mimosa, nativas no Estado do Rio Grande do Sul. Curitiba: UFPR, 1980. 186f. Dissertação (Mestrado em Engenharia Florestal) - Universidade Federal do Paraná.

Marchiori, J. N. C. Dendrologia das Angiospermas: das Magnoliáceas às Flacurtiáceas. Santa Maria: UFSM, p. 91-95, 1997.

Mattos, J. R. Berberidáceas. In: Reitz, P. R. Flora Ilustrada Catarinense. Itajaí: Herbário Barbosa Rodrigues, 1967. 15p.

Metcalfe, C. R., Chalk, L. Anatomy of the Dicotyledons. Oxford: Clarendon Press, 1972a. v. 1. p. 59 .

Metcalfe, C. R., Chalk, L. Anatomy of the Dicotyledons. Oxford: Clarendon Press, $1972 b$. v. 2. p. 905.

Pio Corrêa, M. Dicionário das plantas úteis do Brasil. Rio de Janeiro: Imprensa Nacional, 1926 -1978. v. 2. p. 596-597.

Pontiroli, A. Berberidaceae. In: Cabrera, A. L. Flora de la Provincia de Buenos Aires. Buenos Aires: Colección Cientifica del I.N.T.A, 1997.v. 3, p. 257-260.

Rambo, B. O elemento andino no pinhal riograndense. Anais Botânicos, Itajaí, n. 3, p. 7-39, 1951.

Record, S. J., Hess, R. W. Timbers of the New World. New Haven: Yale University Press, 1949. $639 \mathrm{p}$.

Troncoso, N. S. Berberidaceae. In: Burkart, A. Flora Ilustrada de Entre Rios (Argentina). Buenos Aires: Coleccion Cientifica del INTA, 1987. v. 6. p. 321-323.

Schultz, A. R. Os nomes científicos e populares das plantas do Rio Grande do Sul. Porto Alegre: PUC/ EMMA, 1975. 164p.

Waechter, J. L. Padrões geográficos na flora atual do Rio Grande do Sul. Ciência \& Ambiente, Santa Maria, n. 24, p. 93-108, 2002. 